\title{
UNIVERSITYOF
}

FORWARD

THINKING

WESTMINSTER用

WestminsterResearch

http://www.westminster.ac.uk/westminsterresearch

\section{What are the key features of Orthorexia Nervosa and influences \\ on its development? A qualitative investigation?}

Cheshire, A., Berry, M. and Fixsen, Alison

NOTICE: this is the authors' version of a work that was accepted for publication in

Appetite. Changes resulting from the publishing process, such as peer review, editing, corrections, structural formatting, and other quality control mechanisms may not be reflected in this document. Changes may have been made to this work since it was submitted for publication. A definitive version was subsequently published in Appetite, DOI: 10.1016/j.appet.2020.104798, 2020.

The final definitive version in Appetite is available online at:

https://dx.doi.org/10.1016/j.appet.2020.104798

(C) 2020. This manuscript version is made available under the CC-BY-NC-ND 4.0 license https://creativecommons.org/licenses/by-nc-nd/4.0/

The WestminsterResearch online digital archive at the University of Westminster aims to make the research output of the University available to a wider audience. Copyright and Moral Rights remain with the authors and/or copyright owners. 
What are the key features of Orthorexia Nervosa and influences on its development? A qualitative investigation

\section{Introduction}

Orthorexia nervosa (ON) refers to an unhealthy fixation with healthy eating, where extreme diets based on perceived quality (not quantity) of food consumed can lead to psychological, physical and social impairments (Bratman, 1997). The name 'orthorexia nervosa' was coined by Steve Bratman in 1997 (Bratman, 1997), with the first peer-reviewed, empirical article appearing in the literature in 2004 (Donini, Marsili, Graziani, Imbriale, \& Cannella, 2004). To date, no formal diagnosis of ON exists in the Diagnostic and Statistical Manual for Mental Disorders (DSM-5) (American Psychiatric Association, 2013), however, a number of diagnostic criteria have been proposed (Cena et al., 2019; Dunn \& Bratman, 2016; Moroze, Dunn, Craig Holland, Yager, \& Weintraub, 2015). Whilst some variation between criteria exists, definitions commonly describe the following: an obsessive focus on eating foods that are considered healthy or pure; compulsive behaviour or mental preoccupation related to foods considered unhealthy and; emotional distress and fear linked to unhealthy food and its potential effects on the body and health. Additionally, definitions highlight a need for the preoccupation with healthy eating to become impairing in some way (e.g. socially, physically, emotionally or financially) for this to be described as $\mathrm{ON}$, and to distinguish this clinically significant problem from exceptionally healthy eating behaviours.

Media attention on ON preceded significant academic study on the topic (although the academic literature is now catching up). Indeed, Håman, Barker-Ruchti, Patriksson and Lindgren (2016) were able to dedicate a whole study to how ON has been presented in the popular media after its conception by Bratman in 1997. Some researchers suggest that the prominence of $\mathrm{ON}$ in the media is in fact a backlash against the current moral judgements attached to food choice and aggressive healthism in society, a 'crystallization of apprehensions regarding healthist ideologies', which positions individuals as solely responsibility for their health and well-being (Håman et al., 2016). In all, understanding this new concept has proved challenging: the lack of a DSM-5 diagnostic category and conflicting diagnostic 
criteria, along with the media interest and debate, have left researchers seeking to understand and reach consensus on the key features of ON (Bauer, Fusté, Andrés, \& Saldaña, 2018). For example, Gleaves, Graham and Ambwani (2013) ask, 'does ON even exist as described?', while Bratman (2016) reflects on the role of exercise and wanting to look 'fit' in relation to ON.

A key debate concerns whether ON deserves recognition as a unique disorder, or whether it is a variant of the other eating disorders listed in the DSM-5. Much of this is to do with the substantial fluidity between diagnosis of eating disorders and their overlap with other psycho-medical conditions such as anxiety and obsessive compulsive disorders (Dell'Osso et al., 2016). One key differentiation posited between $\mathrm{ON}$ and anorexia/bulimia is that that the former focuses on the quality of the food, whereas the latter focuses on the quantity of food (Bratman, 1997; Chaki, Pal, \& Bandyopadhyay, 2013). However, while weight loss was not described as a goal of those with ON tendencies in the original literature, there is increasing recognition that some people adopt $\mathrm{ON}$ behaviours as a means of losing weight or, in contrast to anorexic reasons for wanting to lose weight, may be seeking to achieve and ideal image of health/wellness and weight or due to the increasing conflation of 'healthy' with 'low calorie' food (Bratman, 2016). Others suggest that ON may be classified under 'avoidant/restrictive food intake disorder' (ARFID), (Chaki et al., 2013; Dunn \& Bratman, 2016; Mathieu, 2005) as both manifest as a concern for the adverse consequences of eating specific foods (American Psychiatric Association, 2013). However the former largely manifests from teens to young adulthood as part of a pathological drive to be healthy (Bratman, 1997), while the latter generally manifests in infancy or early childhood and is characterised by a lack of interest in food and previous adverse experience with food (American Psychiatric Association, 2013). Typically, those with ARFID would not present with body image concerns. Those with ON tendencies may be given a 'other specified' or 'unspecified' feeding or eating disorder (ED) diagnosis, as in DSM-5 this category applies to presentations of EDs which cause significant distress and social or occupational impairment but fail to meet the full criteria of another ED diagnostic class (APA, 2013: 353). In summary, classifying eating disorders is a complex business, even DSM- 5 classified eating disorders overlap and intersect with one another in ways that confound experts and invite alterations in diagnosis (Mortimer, 2019). 
2 Literature on $\mathrm{ON}$ is predominantly quantitative, focusing on utilisation of questionnaires to assess prevalence in specific populations and correlates of ON tendencies (e.g. demographics, psychological profile) (Cena et al., 2019; Håman, Barker-Ruchti, Patriksson, \& Lindgren, 2015). These studies have reported a high prevalence of ON tendencies in populations including US residents, dieticians, opera singers, athletes, body builders and yoga practitioners (Chaki et al., 2013; Herranz Valera, Acuña Ruiz, Romero Valdespino, \& Visioli, 2014). There are contradictory findings regarding the prevalence of ON tendencies in men and women (McComb \& Mills, 2019). However, these findings need to be treated with caution as significant concerns have been raised about the quality of current ON questionnaires (Missbach, Dunn, \& Konig, 2016). For example, the ORTO-15 measure has been criticised for failing to use a definition of $\mathrm{ON}$ to support scale development (Bratman, 2016) and for being unable to distinguish between healthy eating and pathologically healthy eating (Donini, Marsili, Graziani, Imbriale, \& Cannella, 2005; Dunn, Gibbs, Whitney, \& Starosta, 2017).

Qualitative work on ON is limited; studies in this area have concluded that more qualitative research on $\mathrm{ON}$ is needed in order to examine individuals' perceptions and experiences of $\mathrm{ON}$ tendencies and to help us better understand its key characteristics (Cena et al., 2019; Håman et al., 2015; Strahler, Hermann, Walter, \& Stark, 2018). Existing case studies of individuals hospitalised with disordered eating describing ON type behaviours point to the onset of patient's issues occurring when they altered their diets to help with health problems, which then escalated into an obsession with healthy eating. Despite weight loss, no fear of gaining weight was observed (Moroze et al., 2015; Park et al., 2011; Zamora, Bonaechea, Sanchez, \& Rial, 2005). Four qualitative studies have been published in this area (Cinquegrani \& Brown, 2018; Håman, Lindgren, \& Prell, 2017; Musolino, Warin, Wade, \& Gilchrist, 2015; Rangel, Dukeshire, \& MacDonald, 2012; Ryman, Cesuroglu, Bood, \& Syurina, 2019; Syurina, Bood, Ryman, \& Muftugil-Yalcin, 2018), although none of these studies speak exclusively to people with orthorexic tendencies or with the health professionals treating them. These studies focus on weaving theoretical perspectives with $\mathrm{ON}$ or diet narratives, widening the concept from being solely at the level of the individual, to exploring the influences of societies on ON. They explore concepts 
including healthism (the dominant health ideology in Western societies which places emphasis on individual responsibility for health) and moral citizenship (a good citizen, one who behaves in an ethical manner) (Håman et al., 2017; Nicolosi, 2006; Rangel et al., 2012); illusio (Bourdieu, 1986) (Bourdieu's exploration of being 'caught up in the game'); and health norms (Becker, 1963; Håman et al., 2017). One key emerging theory appears to be that of the 'orthorexic society' (Nicolosi, 2006; Rangel et al., 2012), which describes Western society's hyper-reflexivity around food choices. Driven by conflicting information regarding the 'correct' diet, the distancing of the food consumer and producer, and the focus on individual reasonability for health creates an environment of anxiety around food choice for consumers. Two mixed methods papers from the same research study (Ryman et al., 2019; Syurina et al., 2018) describe how interviews were conducted with mental health professionals who were seeing at least one ED patient per year, and their opinions sought concerning ON as a diagnosis. Interviewed participants believed that the availability of food and increased chronic health conditions in Western cultures underpinned influences on the development of ON which included attempts to obtain beauty ideals, individualism and being in control.

In summary, an understanding of ON is still under development. Quantitative research has been hampered by lack of a definitive definition- and how can ON be measured quantitatively when it is not clear exactly what $\mathrm{ON}$ is? For new and emerging topics, qualitative research can help uncover key features of a subject which is clearly needed here. However, to date no study has sought the perspectives of those with ON tendencies by speaking directly and exclusively to them, or the health professionals working with them. This study fills an important gap in the literature by speaking to people with ON tendencies (those displaying what is agreed to be the defining ON feature - obsessively preoccupied with healthy eating) and those working with them, with the aim of understanding the key, defining ON features and what factors might influence its development.

\section{Methods}

We chose an exploratory, qualitative study design, based on semi-structured interviews with health professionals and individuals with ON tendencies, using a 
purposive convenience approach to sampling. Throughout this report we will refer to participants with ON tendencies as participants, and health professionals working with them as professionals, they are labelled ' $\mathrm{P}$ ' and 'HP' respectively in the results section against quotes used.

\subsection{Participants}

\subsubsection{Individuals with ON tendencies}

Recruitment of participants was done through posters displayed in fitness centres $(n=4)$ and on social media and online eating disorder discussion groups $(n=3)$.

Snowball sampling was also used in that participants recommended people that they knew for the study $(n=3)$. We were aware that recruitment of participants with $O N$ could be challenging because the condition has yet to be clearly defined and an official diagnosis does not exist (Håman et al., 2015). Since ON lacks any formal diagnosis, self-diagnosis is common (Cinquegrani \& Brown, 2018). In line with Cinquegrani and Brown (2018) we chose to include participants that self-reported obsession with healthy eating, an agreed defining ON feature. Inclusion criteria included: self-identifying as currently or previously 'obsessed' with healthy eating or having ON and being 18 years or above. Exclusion criteria were: inability to speak English; diagnosis of major psychiatric disorder; and currently receiving in-patient treatment for an eating disorder. To cater for a lay audience, recruitment strategies for this cohort used lay terminology around key ON features to attract participants i.e. 'has healthy eating taken over your life?'; 'Are you obsessed with healthy eating?' Our interest was in exploring different experiences and perspectives and the use of such questions was designed to indicate to participants that our approach was open minded and investigative rather than prescriptive or clinical.

Ten participants agreed to participate in an interview, but one withdrew prior to the interview as they were concerned it could trigger their disordered eating behaviour. In all, nine participants were interviewed. Participant age range was $23-61$ years old (mean 36.7); six were female and three were male. Seven of the participants were based in the UK and two were based in the United States. All participants had undergraduate level education, see Table 1. 


\subsubsection{Professionals working with individuals with ON tendencies}

Professional were recruited by virtue of their experience of working with individuals with ON tendencies. Recruitment of professionals was through direct contact.

Charities and organisations working in the eating disorders field were approached, firstly with an email and then a follow-up telephone call. Some charities sent emails to their staff about the project, others recommended specific professionals they worked with who were then approached by email. In addition, we posted about the study on the 'Eating Disorder Professionals Resource Network' Facebook group, providing participants with our contact details if they were interested in taking part. Inclusion criteria were professionals working with those with ON tendencies and being 18 years or above. The exclusion criterion was an inability to speak English. Our final cohort of professionals $(n=7)$ included dieticians, clinical psychologists and a family therapist, most of whom had dual qualifications in diet/nutrition and psychology/mental health. Professionals had substantial experience in their respective fields, ranging from three to 35 years experience. All worked regularly with clients with eating disorders, including those with ON tendencies, in a variety of settings including charities, private practice and medical establishments. Four professionals were based in the UK, two were based in the USA and one was based in both the UK and USA. All professionals were female and had been practising for over two years, see Table 1.

Insert Table 1 about here

\subsection{Ethics}

Ethical permission for the study was gained via the Psychology Ethics Committee at the University of Westminster (reference: ETH1718-1186). All participants provided written, informed consent prior to study participation.

\subsection{Procedure}

Once initial contact had been made, all participants and professionals were emailed a copy of the participant information sheet and consent form and were given the opportunity to ask questions about the study. Interviews were arranged face-to-face or via telephone/skype according to participant preference: individuals with ON tendencies, face-to-face $(n=6)$, telephone $(n=3)$; professionals, face-to-face $(n=3)$, 
telephone/skype $(n=3)$. Interviews lasted between 23 and 46 minutes for individuals with ON tendencies, and between 37 and 69 minutes for professionals. All interviews were audio-recorded and transcribed verbatim by a professional transcriber.

The development of the interview schedules was initially informed by a literature review of the area, along with the professional experience of one of the authors as a registered dietitian working with eating disorders. Questions were further developed during discussions among authors. The Berg style of questions was utilised which includes essential questions (focussed on the main issue i.e. questions on the interview schedule), recheck questions which reword participants responses to confirm reliability of information and allow for any clarification of answers, and probing questions to expand and elaborate on answers (e.g. can tell me more about that?) (Minichiello, Aroni, \& Hays, 1995). For individuals with ON tendencies, the interview schedule aimed to explore the full context of individuals' eating choices, including healthy eating choices, reasons for eating healthily, the positive aspects of the diet, and the negative consequences of following their diet. The ON literature focuses on the impact on the individual of adhering to their self-chosen health diet, thus we focused interview questions on the following: ability to carry out daily activities, physical and psychological well-being, finances, and social/educational/work life. Further questions explored various influences on participants' diet. with the interview schedule for professionals focused on their experiences of working with clients, what they saw as the key ON features and how it manifests, its effects on individuals, its relationship to other disorders and sociocultural factors they considered to influence its onset and progression. Two questions which provided particularly insightful information on the topic were; 'can you tell me how it feels when you don't follow your diet or eat unhealthy food?' (individuals with $\mathrm{ON}$ tendencies) and 'what do you consider the tipping point between healthy eating and $O N^{\prime}$ (professionals).

\subsection{Analysis}

Data were analysed using thematic analysis (Braun \& Clarke, 2006). NVivo software was used to explore and ask questions, extract codes and analyse different sections of the data in various ways. Preliminary examination of the data revealed that perspectives on our topic (key ON features and influences on its development) were 
similar for both individuals with ON tendencies and professionals, thus interviews were combined, examined and analysed together. Initially, the first author immersed herself in the data by reading and rereading the transcripts, examining participants thoughts, experiences and positions around key features and influences. Key phrases and insights were highlighted on the transcripts, which were also annotated with initial thoughts. As ideas were generated, they were discussed with the second and third author, who also immersed themselves in the data. For key ON features, it was important to understand the difference between extremely healthy/eccentric eating and an eating disorder. Two interview questions emerged as key to this understanding: 'how do you feel when you can't follow your diet?' for participants, and 'what is the tipping point between healthy eating and ON' for professionals. For participants we were able to compare and contrast narratives of those more and less severely effected in order to develop a fuller understanding of when eating became disordered. A draft of key themes was agreed upon by the authors and data were coded into NVivo.

Data saturation for this study appeared to have been reached. It is widely agreed that the concept of data saturation is a core guiding principle when determining an appropriate sample size and ability to make a contribution to the literature (Morse, 1995). Saturation is defined as 'data adequacy' and is operationalised as no new themes of interest are emerging from the data (Morse, 1995). Although saturation cannot be predicted at the outset, researchers have suggested that it can be reached with as little as 12-15 participants (Baker \& Edwards, 2012), others have suggested that it can occur within the first 12 interviews (Guest, Bunce, \& Johnson, 2006). Richness of data is also important to consider when thinking about saturation (i.e. richer data means less interviews are required) (Morse, 1995). Professionals interviewed for our study had worked with a number of patients/clients with ON/ON tendencies. Therefore they were bringing rich and comprehensive knowledge of multiple patients to the study, which allowed us to achieve saturation with our sample of 16.

In the final stage of the analysis online thread discussions on orthorexia were used to confirm themes. Threads had been collected from an online eating disorder (proanorexia) website and had been selected and analysed for a separate but related 
1 project supervised by the first author (Holmes, 2018). Twelve threads were collected over a 2-month period in $2017 / 18$, those selected contained multiple responses from variety of users around orthorexia topics. Threads were classed as publicly available data. Draft themes for this project were compared with the online threads. Responses on these threads represented more extreme views and behaviours related to orthorexia than our participant narratives, thus the aim of this comparison was to ensure our final themes represented this different dataset. Our examination indicated that our draft themes also fitted the thread, with data differing largely in its extremity rather than its conceptual content.

NVivo was used to generate reports of draft, which were further examined by the first author. Ideas for writing up were then developed, discussed and reviewed by all authors. Finally, our key themes of the study were confirmed, as presented below.

\section{Results}

Here we present the key $\mathrm{ON}$ features and important influences on the development of the condition. Our study integrated perceptions and perspectives from our two cohorts, and highlighted the complexity of $\mathrm{ON}$ as a phenomenon. We hope our findings provide a deeper understanding of $\mathrm{ON}$ and will inform further study. Please see Figure 1 for a diagrammatic representation of our findings.

\section{<insert figure 1 about here>}

\subsection{Key ON features}

Our findings suggest that it is the approach to eating/food and detrimental impact on an individual that are central to ON features, rather than type of healthy diet followed, or food favoured, which can vary greatly in ON. We found no standard consensus of the type of food that is eaten by those with ON features beyond that which they consider healthy for themselves. For our participants, 'healthy' could include a focus on the quality of the food (e.g. organic, lacking on additives), food that can deliver a healthy body (e.g. low fat, build muscle, freedom from health problems), or moral concerns (e.g. veganism, environmental issues). Three key $\mathrm{ON}$ features emerged from the interviews: Rigidity and control, Judgement, and Negative impact. These key features are explored further below. 
$2 \quad 3.1 .1$ Rigidity and control

3 Rigidity and control around food - particularly food choice, preparation and eating routines - emerged as the primary ON feature. Both cohorts agreed that, for those with $\mathrm{ON}$ tendencies, being unable to stick to their chosen diet could be experienced as 'catastrophic' such that the preference might be not to eat at all if the right food was unavailable. Events such as holidays, which are usually viewed as pleasurable, could become a source of anxiety due to potential disruption of food routines. Participants revealed that the more stressed they became, the more the need to control their eating would increase "Holidaying is really hard ... when I don't follow what's normal for me, my routine it's contributed to some form of stress." P5

For those with ON tendencies, ensuring that a diet is rigidly adhered to had become a major mental and practical preoccupation. Being in charge of one's own food preparation was an important element of this. Food shopping and tracking/monitoring eating were time consuming activities for people with ON tendencies, however simply thinking about food and worrying about what to eat appeared to occupy a large proportion of lives.

“You've got your big rocks like relationships, taking care of the dog, maintaining your home and your car and all that jazz and for me right now it's this schoolwork situation. ... and then, food almost occupies as much mental energy as one of those things does." P7

\subsubsection{Judgement}

A second key ON feature that we identified was judging adherence to a 'healthy' diet as the 'right' or moral thing to do, with any deviation from this standard (by the person with ON tendencies or others) seen as inherently wrong or immoral.

"Having a moral judgment because somebody else is eating something that's not considered, what's say orthorexic league, and things like that, the judgment that comes with it. It's very specific with orthorexia from my perspective." HP6 
1 Particularly evident in participants' narratives, was the judgement of any personal dietary digressions as failures. Deviations were interpreted as lack of mental commitment to their personal self-care or health goals, leaving participants feeling as if they had "cheated" and let themselves down. In certain cases, participants' judgements of themselves extended to critiques of others' eating practices, with some participants judging their own nutritional choices as superior to others, e.g. "In my head, I'm just like, 'you pig, that's disgusting' " [comment about an overweight person eating 'junk food'] P5. Such judgements were directed at both categories of foods and those who ate them. Also important was the outward appearance of the individual as a demonstration healthfulness, which in some case cast doubts on other people's outward displays of healthy eating:

"Being fit and in shape and eating healthy is a lot more than just having a salad for lunch five days a week... I see the people all the time, out of shape people at work big or whatever, and always got a damn salad in front of them. Yet it doesn't seem to be doing anything because they're still hugely overweight." P4

\subsubsection{Negatives impacts}

The negative emotional consequences of following a healthy diet emerged as a strong ON feature, although whether ON introduces a new set of problems or exacerbates existing psycho-emotional issues is unclear. Those exhibiting an exaggerated adherence to a "healthy" diet often got stuck in cycles of stress, depression, guilt and feelings of failure. Deviation from eating routines appeared to be a particular source of stress inciting constant worries, and sometimes depression and self-hatred. One of our participants described how even just thinking about eating an ice-cream could send her into an uncontrollable spiral of anxiety:

"If I were like, oh I can't go get ice cream because I just had ice cream yesterday or last week or two weeks ago or whatever and then it starts the mental monkeys of, this is bad, I'm going to feel bad, I'm going to hurt, I'm going to get out of control and eat all the ice cream that exists in the universe. That kind of thing." P7

Participant data presented a contradiction: by attempting to manage their stress though dietary control, they placed additional stresses on themselves. While 
participants acknowledged that they would like to be more relaxed with their diet, some either found this impossible or became stressed/depressed if they did relax their self-discipline.

"You start to feel a bit depressed, physically and emotionally... [if] I'm left with an option of croissant or say a bagel or something, I really can't enjoy it... because all in the back of my mind I said I should be eating my yoghurt right now. So what's supposed to be an enjoyable experience starts to turn into more of a depressing experience." $\mathrm{P} 4$

Socialising with friends/family for a meal or drinks could make strict adherence to diets challenging for those with ON tendencies. For participants concerned about loss of friendships, coping could involve altering what was eaten prior to and after going out, increasing exercise, or purging after a "transgression". Others coped by simply doing less socialising, e.g. "I guess I think I probably naturally tend to eat by myself and alone." P4.

However, self-imposed social isolation could cause conflict with partners, family or friends who became frustrated by their loved ones' idiosyncratic eating or withdrawal. Additionally, the emotional impact of a diet on an individual (e.g. stressed, grumpy) could be a source of friction in relationships.

"It's so bad where it's starting to affect her marriage and her husband is wanting a divorce, you know, 'I can't live like this anymore, we can never go anywhere we're housebound basically because of your food restrictions'." HP2

While recognising that choosing healthy or unadulterated food could be expensive, participants in this study thought that the benefits of their dietary choices outweighed any additional financial outlay. However, cutting out particular food groups could have significant problems as dietary restrictions can lead to nutritional deficiencies. Professionals described clients who, in extreme cases, were suffering quite significant physical health problems due to their restrictive diets. 
1 "I have a patient right now where their grocery bill every month is just insane with all 2 the powders and additives and herbs ... she doesn't have a period, she's got osteopenia, it's not good." HP2

\subsection{Factors and influences on the development of ON}

Professionals in this study agreed that orthorexia nervosa is multi-factorial and a variety of influences must coalesce for healthy eating to progress to a pathology. As we explain below, these influences occur at three intersecting levels, individual (micro) level, external (meso) level and society (macro) level, see Figure 1.

\subsubsection{The Individual}

Health concerns

"When I was younger, I ended up in a wheelchair for about two years and from that I got sort of quite fat so it like, health became a prominent figure in my life from that." P9

"Now that I'm getting older you have to start worrying about things like cancer or I don't know, Parkinson's, Alzheimer's, all that type of stuff." P4

\section{Personality traits}

Professionals in our study discussed how individuals with certain personality (or character) traits - in particular obsessive, perfectionist or A-type personality traits or 'black and white' thinkers - could be susceptible to extreme behaviours including eating. The concern was that these individuals were vulnerable to becoming trapped in ideologies (such as self-care, moral) or the pursuit optimum health, if they were pursued to the point of detriment.

"If you've completely changed your diet of course you feel better. But I think where it then tips is that there's almost like this, I think that's where the compulsiveness kicks 
1 in. There's something that just, that's like, well if I'm really feeling better why can't I feel more, better still? What, maybe I should now cut out gluten because I've heard that gluten does this." HP3

Belief in food as medicine

"I've always thought of food as medicine and it is a preventative measure to eat well and to eat good produce now rather than loads of herbicides, pesticides, all that kind of stuff... I just see it as this is an insurance policy into my long-term health." P5

Several participants attributed their present state of good health to adhering to a healthy diet. Some had originally adopted their diets to improve specific health problems, such as acne and digestive issues, with good results. Improvements in energy levels after enacting dietary changes reinforced participants' beliefs in food as medicine, e.g. "I think the way I do it now, I feel like it keeps me sharp during the day... I have enough energy through the day to be alert and awake and do my best thinking." (P4). A number of participants had undertaken training in the area of diet and nutrition, the content of these courses had supported their personal beliefs around food as a key form of self-care.

"This course was an introduction into how food can be used as medicine basically, but not just food, things like, now self-care's ubiquitous, almost a laughable buzzword these days but doing that for ourselves, taking care of, teaching our patients self-care and how to nourish themselves from different perspectives... [the] weekend course solidified my turn into the Paleo-ish eating patterns." P7

\subsubsection{External influences}

Family, friends and partners 
1 Parental influences emerged as significant in the development of ON tendencies.

2 Professionals in our study identified a number of reasons for this, including what two described as "nurturing issues", by which they inferred that parents were emotionally or physically unavailable. A challenging relationship with parents could express itself through controlled eating behaviour. Having to "satisfy the mother's need for perfection or validation" (HP4) was identified as a potential factor in ON. In both professional and participant interviews, the mother's influence was a frequently discussed topic: "I'm noticing it a lot stemming from the mother" HP5. One participant spoke of how she wished to emulate her mother who was "fabulous ... Growing up we would have the most exquisite meals every night of the week" P6.

Also noted by professionals and participants were the general effects of exposure during childhood and adolescence to extreme attitudes and behaviours, including those related to exercise and diet. One example was that of a child gymnast who was under intensive training and been strongly encouraged by their trainer to follow a particular diet. Another influence identified by one professional was being raised in family which held extreme religious beliefs.

In addition to parental influences, partners could influence dietary choices either through their own behaviour or supporting their partner's obsession.

\section{Past trauma}

Professionals in our study reported on physical and/or emotional trauma experienced by their clients with eating disorders, including those with $\mathrm{ON}$ traits. These traumatic events could lead to problems such as dissatisfaction with the self or the physical body; a need to obsessively control; or, in the case of sexual abuse, as body shame and the need to feel 'clean'.

"I do have a number of cases where it's been brought on by trauma and stress so a loss of a parent early on or horrific sexual abuse or sexual assault cases. If you're not feeling, you don't, especially with the sexual abuse cases if you don't feel comfortable in your body anymore, you feel, I guess, dirty, you feel shamed and all those emotions there are tied in with that experience are really uncomfortable to have to deal with. ... orthorexia becomes a way of 
almost trying to treat that dirtiness like, if I eat clean ${ }^{1}$ then maybe I'll feel clean." HP3

\section{Groups/movements}

Membership to a group often promotes a sense of belonging and inclusion (Cremer \& Tyler, 2005), the normative side of group membership encourages certain beliefs and behaviours, however if these are followed to an extreme they can be detrimental to individual health. For example, one professional expressed concern that, for those already struggling with eating and self-image, clean eating "almost denotes that if you don't eat that way somehow you're eating dirty." (HP3). In addition, in our study, the fitness/body building industry were prominent in participant discourses. Body building requires a complex and challenging schedule of eating and training to achieve the desired physique which, for some who are vulnerable, this controlled lifestyle can tip over into orthorexia.

"In athletes a lot of it seems to come from the social environmental, the expectations, the pressures that, the kind of, so there's, I think there's a biological link in terms of athletes tend to be a certain type of person, they definitely have that characteristic that you would associate." HP3

\subsubsection{Societal influences}

\section{Orthorexic society}

Professionals in our study appeared to agree that society was being increasingly fixated with healthy eating and all had encountered growing numbers of clients with ON tendencies. In addition, our participants reported feeling overwhelmed by contradictory health and diet messages when trying to choose the best diet: "The mixed messages have been a big frustration for me for a long time, it's like, eat this way, not that way, no don't eat that way." P7. Extreme concerns about appearance or aestheticism also emerged as an important factor in the growth of extreme heathy eating. Being perceived as healthy equated to attractiveness, and could drive

\footnotetext{
${ }^{1}$ Clean eating is a dietary strategy which promotes eating whole foods in their natural state and avoiding processed food. Whilst there are variations, the diet often includes raw and plant-based foods, avoiding sugar, gluten and animal products. The diet is typically viewed in positive terms and risks associated with it are currently unclear (Ambwani, Shippe, Gao, \& Austin, 2019).
} 
extreme diets:

"He [client] was preoccupied with the fact that certainly within the gay scene that he was part of, it was just commonplace for guys to walk around with their shirts off, and it was all about the physicality, and how physically attractive you are." HP4

\section{Morality}

The ethics and morality underpinning $\mathrm{ON}$ traits were complex and multi-layered. Judgements reported in our participant narratives positioning healthy food as the 'right choice', pointed to influences from a society where healthism (which places emphasis on individual responsibility for health) and moral citizenship (a good citizen, one who behaves in an ethical manner) dominate. Additionally, some participants expressed a desire to reduce animal suffering and make ethical and environmentally responsible food choices. While this thinking is in line with social and ecological movements, extreme food choices could, our professionals believed, become enmeshed with obsessive behaviour, or be used to disguise an eating disorder. This was particularly the case in those who had other traits associated with eating disorders such as perfectionism:

"Some people can be vegan or eat paleo and be totally fine if they don't have a history of an eating disorder. I think if you have a history of an eating disorder, if you're genetically prone to having an eating disorder or if your personality lends itself that way it's really, really hard to follow paleo, vegan, keto whatever it might be because it's then really hard to jump out of it." HP2

\section{Social media}

Social media constantly exposes people to various societal ideals and group identities, and can engender constant comparison between self and others (Festinger, 1954). In our study, social media and social media groups served as a source of information on dietary regimens and beliefs. They were considered to be influential in validating extreme dietary regimens and beliefs, could be highly challenging for professionals in therapeutic settings: 
"We [therapist and client] need to do this is your goal for this week let's try and do it let's try and get it. And she can go away out of the room feeling like, yep I'm going to do this I'm ready. And then the next day you get a message from her saying 'I was going to do I even made it and then I looked at my Instagram and I saw such and such and she's having something completely different today and I don't feel I can have what I'm having because it almost feels wrong.' " HP3

\section{Discussion}

\subsection{Key findings}

This study sought to redress a gap in the literature on ON by undertaking an exploratory qualitative study to understand its key features and influences on its development. It is not our intention to create a definitive list of features and influences, but rather present ideas and a framework through which ON can be explored in order to support further research, promote discussion and support understanding. Existing studies of ON suggest that it is best conceptualised as having multiple presentations and expressions (Poirier, 2016). However, to our knowledge, our study is the first to draw together key features and potential influences on the development of $\mathrm{ON}$, exploring influences through internal, external and societal levels (Figure 1). One recent study examined ON risk factors and proposed a two-level model, dividing risk factors between social/cultural factors outside of the individual and intra-individual factors (McComb \& Mills, 2019). Risk factors and influences can be viewed as qualitatively different, for example, whilst higher incomes or availability of organic food can be viewed as risk factors, they would not be influences on development, which tend to be higher order constructs. Thus, whilst there are similarities between the models, both make distinctive and unique contributions to our understanding of $\mathrm{ON}$.

A multi-level approach indicates that it is the coalescence of factors at particular points and the interplay between influences on individuals in a particular society, which constitute the pathological state referred to as ON. Thus, for example, while moral standpoints such as those which underpin veganism and beliefs about the medical value of foods do not amount to pathology, when co-occurring with factors such as past trauma, obsessive personalities or over preoccupation and insecurity 
around appearance and identity, the risk of healthy eating becoming pathological increases. In particular, preoccupation with healthy eating in someone with a previous history of EDs appears to be a red flag for professionals in the field. A wider debate concerns how the health promoting and morality messages delivered by society, can, when subverted, create a damaging alter-ego to self-care and moral citizenship.

We now discuss what we consider to be the key ON features and the key influences in its development in more depth.

\subsection{Key ON features}

No formal diagnosis of ON exists in the DSM-5, however a number of diagnostic criteria have been proposed (Cena et al., 2019; Dunn \& Bratman, 2016; Moroze et al., 2015; Setnick, 2013; Varga, Dukay-Szabó, Túry, \& van Furth Eric, 2013), which contain some common ground, but also some variability. We will refer to these diagnostic criteria in this discussion. We also recommend that any future definitive definitions of ON should include the key features identified in this study, which uniquely frames these features within different analytical levels (see Figure 1) and is firmly grounded in the real-life narratives of people who espouse to or treat extreme healthy eating. Our findings confirm that it is the approach to eating/food and detrimental impact on an individual that are central to ON features, rather than type of healthy diet followed or food favoured. Some criteria and studies use terms such as 'clean', 'correct', 'pure', 'safe' to refer to food favoured by those presenting with symptoms of ON (Cena et al., 2019), however whilst these terms may well be used by some of these individuals, our findings suggest that they certainly do not apply to all.

The first key ON feature we identified within our data was rigidity and control around healthy eating. Whilst one set of diagnostic criteria includes 'ridged avoidance' (Moroze et al., 2015), others favour the terms compulsion (Dunn \& Bratman, 2016) or ritualised behaviours (Cena et al., 2019). Our data suggest that rigidity relates not only to avoiding foods but also choice of foods, along with food preparation and routines. Uniquely in studies of ON, our data highlighted that control was a key issue; perceived stress and lack of control in other areas of life often led to increased 
attempts at dietary control. Also highlighted in this study was the time spent on food, including the mental preoccupation with food and/or its physical preparation, which coincides with current $\mathrm{ON}$ diagnostic criteria.

Another key ON feature identified by this study, which is rather neglected by current diagnostic criteria, concerns judgements about food. Current criteria omit or limit this feature to moral judgements/intolerance of other's food choices, however we found judgements about food to be broader. Judgements were made by those in our study about the correct foods to eat, but also moral judgements regarding deviations from this diet. These judgements could be directed at others who deviated but were more often directed inwardly as personal transgressions. Additionally, judgements could extend to needing to present a healthy appearance, as well as eating healthily.

Diagnostic criteria of ON also highlight that dietary restrictions have become impairing in some way. We found that while negative effects of ON were wide ranging, emotional distress and social isolation were particularly impairing for individuals. Again, criteria highlight the need for these impairments to be of clinical significance (e.g. malnutrition or mental health problems) to warrant an $\mathrm{ON}$ classification.

A key debate regards the significance (or not) of weight loss and ON, with the absence of a desire for weight loss being proposed by some as a defining criterion of ON (Cena et al., 2019; Dunn \& Bratman, 2016). More recently Bratman has suggested that a high percentage of people with ON do have a focus on weight loss, as adoption of extreme healthy eating can be a means of disguising anorexia or due to the conflation of low calorie and healthy food (Bratman, 2016). Our study confirmed a preoccupation with weight loss among some participants, and an overlap or continuation of other eating disorder traits (e.g. binging and purging) alongside ON. In other instances, the focus was primarily on muscle gain or 'not becoming fat' (which can be distinguished from being thin). Thus, evidence from our study suggests that people with ON may adjust their diet to achieve their vision of health - which may variously be thin, strong, muscle bound or just 'not fat'. This point also links with body aesthetics which we discuss in the following section 4.3. 
14.3 Influences on the development of ON

2 The ON qualitative literature to date has focused on specific societal influences on the development of $\mathrm{ON}$, and our study has found some support for their findings. Reports from this study's participants describing constant thoughts regarding food choices and feeling overwhelmed by mixed messages about the best diet/foods, fit the notion of the 'orthorexic society' described by Nicolosi (2006). Concerns over appearance, and appearing healthy reported in this study, support findings that argue for a role of aestheticism in the development of ON (Cinquegrani \& Brown, 2018; Syurina et al., 2018), with quantitative data also supporting this finding (Depa, Barrada, \& Roncero, 2019). Additionally, judgements/moralistic views related to healthy diets and concerns regarding animals and the environment described by this

Quantitative research has also shown the amount of social media use and importance placed on social media (particularly Instagram) to be related to $\mathrm{ON}$ tendencies (Turner \& Lefevre, 2017). The current study casts social media as a conduit for extreme health ideologies (supported by Syurina et al., (2018) and Hanganu-Bresch (2019)) and as promoting a sense of identity or group belonging to healthy eating movements. It was this sense of belonging or identification that professionals in our study reported as particularly divisive in the therapy process, with clients sometimes choosing to follow social media influencers' advice rather than the personalised treatment plans developed in therapy. Conversely, online group discussions may, in some cases, engender peer support, facilitate healthy 
1 food choices and recovery from ON behaviours (Fixsen, Berry, \& Cheshire, 2020;

2 Yeshua-Katz, 2015)

At the individual level, we noted beliefs about food as a medicine (or self-care tool) as being an influence on the development of the condition, which is in line with other studies on this topic. Certain diagnostic criteria have included a similar construct'overvalued ideas'- concerning the positive or negative impacts of food (Barthels, Meyer, \& Pietrowsky, 2015; Dunn \& Bratman, 2016). In addition, research highlights the importance of the link between food and health in individuals' minds when making food choices (Rangel et al., 2012). The orthorexic society concept points to how this link can create escalations in individual's perceptions regarding risks related to eating the 'wrong' foods (Nicolosi, 2006; Rangel et al., 2012). In her thesis, Poirier (2016) explores how 'illusions of safety' may influence ON development. The illusion of safety achieved from a strict healthy diet may relate to physical safety (e.g. from threat of illness or death) or psychological safety as a perceived sense of control and self-esteem.

At the individual level of influence, there is significant support in the literature concerning the role of particular personality traits (e.g. obsessive, perfectionist) in ON development (McComb \& Mills, 2019; Syurina et al., 2018). However, other influences on the development of $\mathrm{ON}$ found by this study at the individual and external /relational levels have been less well explored in the social science literature (e.g. past trauma, parental influence), suggesting that future research should seek to explore these more extensively.

\subsection{Study strengths and limitations}

A strength of our study lies in our attempt to combine key features and influences on the development of $\mathrm{ON}$ and provide a representative layered (onion) diagram. We also acknowledge that eating disorders are complex; it is not our intention to oversimply the issue, pathologise expressions of individuality or healthy behaviours, make claims regarding the causes of $\mathrm{ON}$ or provide an exhaustive list of influences on its development. Rather we present here key ON features and important influences on the development of the condition as they emerged from our data, which we hope will provide a deeper understanding of ON and inform further study. 
1 Recruiting participants from only the UK was challenging, thus we also recruited participants based in the USA. This introduced increased heterogeneity and variability into the sample, but nevertheless resulted in our findings being more generalisable.

5

Whilst data saturation appeared to have been reached for the study questions, given that our sample size was 16 it may be that other studies uncover further insights. We encourage any such studies to suggest updates to our model. For example, we uncovered body shame and the need to feel clean particularly in relation to past trauma. It may be that this dissatisfaction with the body is a more general issue experienced by individuals, not only related to past trauma. Influences at the societal feed into ON tendencies by generating body dissatisfaction. Future research may want to consider exploring this in more detail, by questioning participants specially how they feel about themselves/their body or examining the relationship between ON and self-esteem.

Orthorexia nervosa is currently an unofficial diagnosis, hence there are no official diagnostic criteria which can be used to recruit participants to the studies. Thus, our decision was to recruit participants who self-defined as orthorexic or obsessed with healthy eating. Our method of recruitment may have resulted in participants being recruited to the study who did not have ON, either in terms of differing symptoms to ON or those who's ON tendencies were not severe enough for ON. In practice it was straight forward to draw out common experiences for this group, however a range of severities were included in the study. We were able to turn this to our advantage, comparing and contrasting narratives of those more and less severely effected in order to develop a greater understanding of the differences between extreme healthy eating and a pathology. In addition, our inclusion of professionals and then checking themes against online discussions in more extreme populations, provided a broad dataset through which to understand $\mathrm{ON}$.

The lack of an official diagnosis also raises the issue as to whether or not ON can be viewed a distinct eating disorder and whether we as researchers should we be studying it as such. The issue remains a contested one that lies beyond the scope of 
1 the current paper. A further paper by the authors on this topic explores ON from a social constructionist perspective, expanding on the central arguments concerning the social and relational dimensions of ON identified and discussed in this paper (Fixsen et al., 2020).

\subsection{Study implications}

For other scholars in the ED field, we hope that our research will contribute to the conversation on defining $\mathrm{ON}$ help to establish whether or not ON can be viewed as a unique disorder. We have provided recommendations regarding key diagnostic criteria that should be utilised in any future definition of ON/ON behaviour (see Figure 2). We have highlighted gaps in the literature that require exploration, including influences on the development of $\mathrm{ON}$ at the individual and

\section{Author contributions} external/relational levels. In addition, we highlighted the need to understand more about how social media can both positively and negatively influence $\mathrm{ON}$ tendencies.

In terms of clinical implications, we emphasise that holding single factors (e.g. social media, veganism) responsible for $\mathrm{ON}$ is inappropriate and over-simplistic. Rather, it is important for the reasons behind any pathological feelings/thoughts/behaviours to be broken down and explored in a clinical setting, in order to understand underlying issues driving these manifestations. Our study the complexity of different views and perspectives on eating practices, suggesting that any generalised pathologizing of extreme healthy eating should be avoided. (Håman et al., 2016; Nicolosi, 2006)

\section{Acknowledgements}

We would like to thank:

- All our participants for giving up their time to take part in this research

- Charlotte Holmes for collecting and allowing us to use the online 'orthorexia threads', which was undertaken as part of her undergraduate dissertation 
AC designed the study, recruited professional participants, analysed the data, wrote the first draft of the article and compiled co-author feedback for submission. MB recruited collected data from participants with ON tendencies, analysed the data for key ON features, which informed the analysis conducted by $A C$, reviewed the manuscript and provided feedback. AF recruited and collected data from professional participants and reviewed and added to the manuscript. All authors discussed and debated themes by email and in face-to-face meetings. All authors have approved the final article.

\section{Funding statement}

This work was supported by Perdana University - Centre for Psychological Medicine, Kuala Lumpur, Malaysia. The funders had no role in the research design, data collection and analysis, writing the report, and the decision to submit the article for publication.

\section{Competing interest statement}

Declarations of interest: none

\section{References}

Ambwani, S., Shippe, M., Gao, Z., \& Austin, S. B. (2019). Is \#cleaneating a healthy or harmful dietary strategy? Perceptions of clean eating and associations with disordered eating among young adults. Journal of Eating Disorders, 7(1), 17. doi:10.1186/s40337-019-0246-2

American Psychiatric Association. (2013). Diagnostic and statistical manual of mental disorders (5th ed.). Arlington, VA: American Psychiatric Publishing.

Baker, S., \& Edwards, R. (2012). How many qualitative interviews is enough? . Retrieved from http://eprints.brighton.ac.uk/11632/1/how many interviews.pdf

Barthels, F., Meyer, F., \& Pietrowsky, R. (2015). Die Düsseldorfer Orthorexie SkalaKonstruktion und Evaluation eines Fragebogens zur Erfassung ortho-rektischen Ernährungsverhaltens. Zeitschrift für Klinische Psychologie und Psychotherapie, 44(2), 97-105. doi:10.1026/1616-3443/a000310

Bauer, S. M., Fusté, A., Andrés, A., \& Saldaña, C. (2018). The Barcelona Orthorexia Scale (BOS): development process using the Delphi method. Eating and Weight Disorders - Studies on Anorexia, Bulimia and Obesity. doi:10.1007/s40519-018-0556-4

Becker, H. S. (1963). Outsiders: Studies in the sociology of deviance. New York: The Free Press. 
Bourdieu, P. (1986). The Forms of Capital. In J. Richardson (Ed.), Handbook of Theory and Research for the Sociology of Education (pp. 241-258). New York: Greenwood Press.

Bratman, S. (1997). The health food eating disorder. Yoga Journal, 4250 (September/October).

Bratman, S. (2016). Orthorexia: An Update. Retrieved from http://www.orthorexia.com/orthorexia-an-update/

Braun, V., \& Clarke, V. (2006). Using thematic analysis in psychology. Qualitative Research in Psychology, 3(2), 77-101.

Cena, H., Barthels, F., Cuzzolaro, M., Bratman, S., Brytek-Matera, A., Dunn, T., . . . Donini, L. M. (2019). Definition and diagnostic criteria for orthorexia nervosa: a narrative review of the literature. Eating and Weight Disorders - Studies on Anorexia, Bulimia and Obesity. doi:10.1007/s40519-018-0606-y

Chaki, B., Pal, S., \& Bandyopadhyay, A. (2013). Exploring scientific legitimacy of orthorexia nervosa: a newly emerging eating disorder. Journal of Human Sport and Exercise 8(4), 1045-1053. doi:10.4100/jhse.2013.84.14

Cinquegrani, C., \& Brown, D. H. K. (2018). 'Wellness' lifts us above the Food Chaos': a narrative exploration of the experiences and conceptualisations of Orthorexia Nervosa through online social media forums. Qualitative Research in Sport, Exercise and Health, 10(5), 585-603. doi:10.1080/2159676X.2018.1464501

Cremer, D. d., \& Tyler, T. R. (2005). Am I Respected or Not?: Inclusion and Reputation as Issues in Group Membership. Social Justice Research, 18(2), 121-153. doi:10.1007/s11211-005-7366-3

Dell'Osso, L., Abelli, M., Carpita, B., Pini, S., Castellini, G., Carmassi, C., \& Ricca, V. (2016). Historical evolution of the concept of anorexia nervosa and relationships with orthorexia nervosa, autism, and obsessive-compulsive spectrum. Neuropsychiatric disease and treatment, 12, 1651-1660. doi:10.2147/NDT.S108912

Depa, J., Barrada, J. R., \& Roncero, M. (2019). Are the Motives for Food Choices Different in Orthorexia Nervosa and Healthy Orthorexia? . Nutrients 11, 697.

Donini, L. M., Marsili, D., Graziani, M. P., Imbriale, M., \& Cannella, C. (2004). Orthorexia nervosa: A preliminary study with a proposal for diagnosis and an attempt to measure the dimension of the phenomenon. Eating and Weight Disorders - Studies on Anorexia, Bulimia and Obesity, 9(2), 151-157. doi:10.1007/bf03325060

Donini, L. M., Marsili, D., Graziani, M. P., Imbriale, M., \& Cannella, C. (2005). Orthorexia nervosa: Validation of a diagnosis questionnaire. Eating and Weight Disorders Studies on Anorexia, Bulimia and Obesity, 10(2), e28-e32. doi:10.1007/bf03327537

Dunn, T. M., \& Bratman, S. (2016). On orthorexia nervosa: A review of the literature and proposed diagnostic criteria. Eating Behaviors, 21(Supplement C), 11-17. doi:https://doi.org/10.1016/i.eatbeh.2015.12.006

Dunn, T. M., Gibbs, J., Whitney, N., \& Starosta, A. (2017). Prevalence of orthorexia nervosa is less than $1 \%$ : data from a US sample. Eating and Weight Disorders - Studies on Anorexia, Bulimia and Obesity, 22(1), 185-192. doi:10.1007/s40519-016-0258-8

Festinger, L. (1954). A Theory of Social Comparison Processes. Human Relations, 7(2), 117-140. doi:10.1177/001872675400700202

Fixsen, A., Berry, M., \& Cheshire, A. (2020). The social construction of a concept orthorexia nervosa: Morality narratives and psycho-politics. Qualitative Health Research, In press.

Gleaves, D. H., Graham, E. C., \& Ambwani, S. (2013). Measuring 'Orthorexia': Development of the Eating Habits Questionnaire. . The International Journal of Educational and Psychological Assessment, 12(2), 1-18. Retrieved from https://scholar.dickinson.edu/faculty publications/427/

Guest, G., Bunce, A., \& Johnson, L. (2006). How Many Interviews Are Enough?:An Experiment with Data Saturation and Variability. Field Methods, 18(1), 59-82. doi:10.1177/1525822×05279903 
Håman, L., Barker-Ruchti, N., Patriksson, G., \& Lindgren, E.-C. (2015). Orthorexia nervosa: An integrative literature review of a lifestyle syndrome. International Journal of Qualitative Studies on Health and Well-being, 10(1), 26799. doi:10.3402/qhw.v10.26799

Håman, L., Barker-Ruchti, N., Patriksson, G., \& Lindgren, E.-C. (2016). The framing of orthorexia nervosa in Swedish daily newspapers: A longitudinal qualitative content analysis. Scandinavian sport studies forum, 7, 27-46.

Håman, L., Lindgren, E.-C., \& Prell, H. (2017). "If it's not Iron it's Iron f*cking biggest Ironman": personal trainers' views on health norms, orthorexia and deviant behaviours. International Journal of Qualitative Studies on Health and Well-being, 12(sup2), 1364602. doi:10.1080/17482631.2017.1364602

Hanganu-Bresch, C. (2019). Orthorexia: eating right in the context of healthism. Medical Humanities, medhum-2019-011681. doi:10.1136/medhum-2019-011681

Herranz Valera, J., Acuña Ruiz, P., Romero Valdespino, B., \& Visioli, F. (2014). Prevalence of orthorexia nervosa among ashtanga yoga practitioners: a pilot study. Eating and Weight Disorders - Studies on Anorexia, Bulimia and Obesity, 19(4), 469-472. doi:10.1007/s40519-014-0131-6

Holmes, C. (2018). Exploring Issues Related to Orthorexia through an Online Sharing Platform. (Undergraduate dissertation). University of Westminster,

Mathieu, J. (2005). What Is Orthorexia? Journal of the American Dietetic Association, 105(10), 1510-1512. doi:https://doi.org/10.1016/j.jada.2005.08.021

McComb, S. E., \& Mills, J. S. (2019). Orthorexia nervosa: A review of psychosocial risk factors. Appetite, 140, 50-75. doi:https://doi.org/10.1016/i.appet.2019.05.005

Minichiello, V., Aroni, R., \& Hays, T. (1995). In-depth Interviewing: Principles, Techniques, Analysis. Melbourne: Longman Cheshire.

Missbach, B., Dunn, T. M., \& Konig, J. S. (2016). We need new tools to assess Orthorexia Nervosa. A commentary on "Prevalence of Orthorexia Nervosa among College Students Based on Bratman's Test and Associated Tendencies". Appetite, 108, 521.

Moroze, R. M., Dunn, T. M., Craig Holland, J., Yager, J., \& Weintraub, P. (2015). Microthinking About Micronutrients: A Case of Transition From Obsessions About Healthy Eating to Near-Fatal "Orthorexia Nervosa" and Proposed Diagnostic Criteria. Psychosomatics, 56(4), 397-403. doi:10.1016/j.psym.2014.03.003

Morse, J. M. (1995). The Significance of Saturation. Qualitative Health Research, 5(2), 147149. doi:10.1177/104973239500500201

Mortimer, R. (2019). Pride Before a Fall: Shame, Diagnostic Crossover, and Eating Disorders. Journal of bioethical inquiry, 16(3), 365-374. doi:10.1007/s11673-01909923-3

Musolino, C., Warin, M., Wade, T., \& Gilchrist, P. (2015). 'Healthy anorexia': The complexity of care in disordered eating. Social Science \& Medicine, 139, 18-25. doi:https://doi.org/10.1016/i.socscimed.2015.06.030

Nicolosi, G. (2006). Biotechnologies, alimentary fears and the orthorexic society. Tailoring Biotehcnologies, 2(3), 37-56.

Park, S. W., Kim, J. Y., Go, G. J., Jeon, E. S., Pyo, H. J., \& Kwon, Y. J. (2011). Orthorexia Nervosa with Hyponatremia, Subcutaneous Emphysema, Pneumomediastimum, Pneumothorax, and Pancytopenia. Electrolyte Blood Press, 9(1), 32-37. Retrieved from http://synapse.koreamed.org/DOIx.php?id=10.5049\%2FEBP.2011.9.1.32

Poirier, H. (2016). An Investigation into the Illusion of Safety Construct of Orthorexia Nervosa. (PhD). Connecticut College, Retrieved from https://search.proquest.com/openview/356df2d3b4b660f75b18f508441e93d5/1?pqorigsite $=$ gscholar \&cbl=18750\&diss $=y$

Rangel, C., Dukeshire, S., \& MacDonald, L. (2012). Diet and anxiety. An exploration into the Orthorexic Society. Appetite, 58(1), 124-132. doi:https://doi.org/10.1016/i.appet.2011.08.024 
Ryman, F. V. M., Cesuroglu, T., Bood, Z. M., \& Syurina, E. V. (2019). Orthorexia Nervosa: Disorder or Not? Opinions of Dutch Health Professionals. Frontiers in Psychology, 10(555). doi:10.3389/fpsyg.2019.00555

Setnick, J. (2013). The eating disorders clinical pocket guide: quick reference for healthcare providers, second edition. Dallas: Academy of Nutrition and Dietetics.

Strahler, J., Hermann, A., Walter, B., \& Stark, R. (2018). Orthorexia nervosa: A behavioral complex or a psychological condition? , 7(4), 1143. doi:10.1556/2006.7.2018.129

Syurina, E. V., Bood, Z. M., Ryman, F. V. M., \& Muftugil-Yalcin, S. (2018). Cultural Phenomena Believed to Be Associated With Orthorexia Nervosa - Opinion Study in Dutch Health Professionals. Frontiers in Psychology, 9, 1419-1419. doi:10.3389/fpsyg.2018.01419

Turner, P. G., \& Lefevre, C. E. (2017). Instagram use is linked to increased symptoms of orthorexia nervosa. Eating and Weight Disorders - Studies on Anorexia, Bulimia and Obesity, 22(2), 277-284. doi:10.1007/s40519-017-0364-2

Varga, M., Dukay-Szabó, S., Túry, F., \& van Furth Eric, F. (2013). Evidence and gaps in the literature on orthorexia nervosa. Eating and Weight Disorders - Studies on Anorexia, Bulimia and Obesity, 18(2), 103-111. doi:10.1007/s40519-013-0026-y

Yeshua-Katz, D. (2015). Online Stigma Resistance in the Pro-Ana Community. Qualitative Health Research, 25(10), 1347-1358. doi:10.1177/1049732315570123

Zamora, C., Bonaechea, B., Sanchez, G., \& Rial, R. (2005). Orthorexia nervosa. A new eating behavior disorder? Actas Espanolas Psiquiatría, 33(1), 66-68. 